\title{
VII. On Swan's prism photometer, commonly called Lummer and Brodhun's photometer
}

\author{
Prof. C.G. Knott D.Sc.
}

To cite this article: Prof. C.G. Knott D.Sc. (1900) VII. On Swan's prism photometer, commonly called Lummer and Brodhun's photometer , Philosophical Magazine Series 5, 49:296, 118-120, DOI: $10.1080 / 14786440009463827$

To link to this article: http://dx.doi.org/10.1080/14786440009463827

Published online: 21 Apr 2009.

Submit your article to this journal $₫$

Џ Article views: 2

Q View related articles $\square$ 


\section{Prof. C. G. Knott on Swan's Prism Photometer.}

principle that solids are regarded as rigid, strings as inextensible, and so on. And it is upon the recognition of such constraints that Lagrange's method is founded. But the law of equal partition disregards potential energy. However great may be the energy required to alter the distance of the two atoms in a diatomic molecule, practical rigidity is never secured, and the kinetic energy of the relative motion in the line of junction is the same as if the tie were of the feeblest. The two atoms, however related, remain two atoms, and the degrees of freedom remain six in number.

What would appear to be wanted is some escape from the destructive simplicity of the general conclusion relating to partition of kinetic energy, whereby the energy of motions involving larger amounts of potential energy should be allowed to be diminished in consequence. If the argument, as above set forth after Maxwell, be valid, such escape must involve a repudiation of Maxwell's fundamental postulate as practically applicable to systems with an immense number of degrees of freedom.

VII. On Swan's Prism Photometer, commonly called Lummer and Brodhun's Photometer. By Prof. C. G.Knotr, D.Sc.*.

IN N 1849 William Swan, subsequently Professor of Natural Philosophy in the University of St. Andrews, read a paper "On the Gradual production of Luminous Impressions on the Eye and other Phenomena of Vision " before the Royal Society of Edinburgh (see Transactions, vol. xvi.). This paper contains some results of bigh interest, but I have no recollection of ever having seen it referred to in modern literature on the subject.

On April 4, 1859, Professor Swan gave a second paper on the same subject, much briefer than the first, and entirely occupied with descriptions of greatly improved forms of apparatus (see Transactions, vol. xxii.). Among the forms of apparatus described is his "Prism Photometer." 'This is simply and solely the form of photometer described in 1889 , exactly thirty years later, by Lummer and Brodhun, and named after them in all recent literature (see Zeitschrift für Instrumentenkunde, Bd. ix.). I cannot do better than give Swan's description in full, and reproduce his own diagram. He writes:- "An arrangement which, from an imporfect

* Communicated by the Author: read before the Royal Society of Edimburgh, Dec. 17th, 1899. 
Prof. C. G. Knott on Swan's Prism Photometer. 119

trial I have made of it, promises to succeed well for comparing the brightness of the illuminated apertures, may be made by cementing together two equal and similar rectangular glass prisins $\mathrm{ABC}, \mathrm{BCD}$, so as to form a parallelopiped, by means of a small portion of Canada balsam, which, when the prisms are pressed together, expands into a circular thin film $E$. The illuminated apertures $C^{\prime}, D^{\prime}$ in the screens are

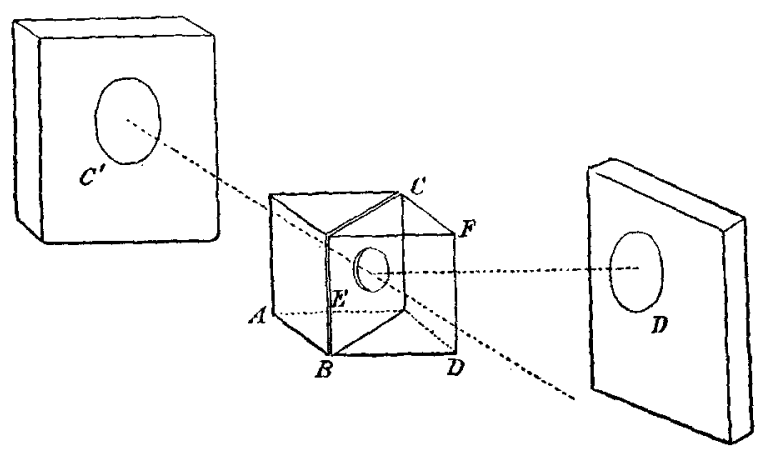

placed opposite to the faces $A C, C D$, and the observer looks through the face $\mathrm{BF}$. The light transmitted through $\mathrm{AC}$, and falling on $\mathrm{BC}$, will be totally reflected, except the portion which falls on the film of Canada balsam at $\mathbb{E}$, which will bo nearly all transmitted to the eye of the observer. The light which is transmitted through the face $\mathrm{CD}$ will be totally reflected to the eye by the face $B C$, except what falls on the Canada balsam at $\mathrm{E}$, which will be nearly all transmitted. The spot $\mathbf{E}$ will appear of a different brightness from the rest of the surface $B C$, except when the light totally reflected by $B C$ is equal in intensity to the sum of the lights transmitted and reflected at $\mathrm{E}$. The spot $\mathrm{E}$ will then disappear, owing to the whole surface of $\mathrm{BC}$, including tho spot, becoming uniformly bright. Assuming that the light partially reflected at $\mathrm{E}$ has a constant ratio to that totally reflected by the rest of the surface $\mathrm{BC}$, and to that transmitted by $\mathrm{A} \mathrm{C}$, it is obvious that the squares of the distances of the flame from the aperture $\mathrm{D}^{\prime}$ when the spot $\mathrm{E}$ disappears will give the ratio of the intensities of the lights transmitted by the aperture C'."

Swan's intention was to publish the results obtained with his improved apparatus; but we can find no record of the continuation of the work. Probably he obtained nothing that materially added to or in any way affected the accuracy 
of his earlier results ; and it was not his habit to write for mere writing's sake.

But whatever may have been the real reason for his subsequent silence, there is not the least doubt that Swan invented, described, constructed, and used, thirty years before the scientific world was ready for it, the prism-photometer which Lummer and Brodhun had to re-invent. One of the photometers constructed by Swan himself is now among the apparatus of the Physical Laboratory of Edinburgh University, having been purchased by Professor Tait some years ago along with the best part of Professor Swan's private collection. This photometer is in regular use in the Laboratory.

In the same collection were also two other small prisms intended for the same purpose, but not made up. 'The lid of the small box containing them still bears the inscription in Professor Swan's own handwriting:- "Pair of fine plateglass prisms made for me by Cooke (1870) for my prismphotometer." This inscription, written fully ten years after the first published description, shows that Swan was in the habit of using his photometer.

The fact that Swan had forestalled Lummer and Brodhun in the invention and construction of an ingenious form of photometer has of course been familiar to all officialiy connected with the Edinburgh University Physical Laboratory for some yeurs past. Recently, having occasion to enquire somewhat closely into the history of photometric metlods, I determined to make a systematic search through Swan's published papers, which for the most part treat of optical subjects. I had not far to search ; for on the plate illustrating the second paper named above I recognized at a glance the prism-photometer, and immediately thereafter discovered the descriptive paragraph. My expectation at most was to find some incidental reference to the instrument. To my surprise I found as complete a description of the essential instrument as anyone could desire to find. It will remain always a matter of no small astonishment that such an important contribution to knowledge should have escaped the notice of the myriad workers in photometry. In Swan's day there was not the same great interest taken in the subject; but that is no excuse for present neglect.

Swan's photometer was given to a world not ready for its reception. Let us now, who know its value, not forget that it is "Swan's" photometer. 